\title{
FORGIVING IS NOT ONLY FORGETTING (PHENOMENOLOGICAL STUDY ON FORGIVENESS IN INDIVIDUAL WHO EXPERIENCES A FRIENDSHIP CONFLICT)
}

\author{
Zulmi Ramdani \\ S.Psi (Bachelor of Psychology), Master Candidate on Psychometrics in Gadjah Mada University- \\ Yogyakarta, Indonesia, zulmiramdani94@gmail.com
}

\begin{abstract}
The friendship conflicts are associated with the emergence of hostile feelings between people who feel victimized by another person. This kind of conflict will damage the moral and relationship between them. One thing that can be done by humans to solve this problem is by forgiving. Forgiveness is not an easy thing to do, considering that the offended individual may have different reactions. This concept of forgiveness will be not only concerning on what happens in the heart, but also having a willingness to restart usual interaction and behavior. This study used a phenomenological approach which was aimed to identify the meaning and the process of forgiving. The result of investigating 3 subjects carried out three important things that must exist in the process of forgiving, i.e. basic personal values, understanding of offenders, and positive efforts. Basic personal values will be individual characteristics in solving conflicts regarding on the values of kindness, love, and humanity. Understanding of offender will increase our empathy toward the feelings of others. Meanwhile, the positive effort will be our main step that forgiving is not only saying sorry, but also having sincerity in the heart which is then shown with a willingness to reinitiate and interact with the person.
\end{abstract}

Keywords: forgiving; friendship conflict; phenomenology

\section{INTRODUCTION}

Conflict is a situation that will be accepted by each individual in accordance with its development period. At each level, the individual has different variety of conflicts. One of the conflicts that often occur in human life is the conflict of friendship (Boyle, Saklofske, \& Matthewes, 2015). A friendship conflict is linked to the emergence of feelings of hostility between someone who feels victimized with another person who feels a perpetrator. A Conflict like this will damage moral and relationship between two or more people who do it. It will also harm the person's physical environment, their physiological, psychological and spiritual aspects (Boyle et al., 2015).

The disharmony and inconvenience of the hostilities that occur in friendship are often due to simple things, which do occur as a form of challenge in their relationships. But often the focus of the situation is a 
relationship that is no longer harmonious and position itself in the most correct situation according to each thought. Based on preliminary studies conducted using group discussion methods in an academic community in Yogyakarta, the factors that usually inhibit rapidly resolved friendship conflicts are too close and selfish sense of the person. A close relationship will lead people to unlimited friendships. So when there is the slightest misunderstanding, the chances of conflict are quite big. It is also influenced by feelings of selfishness or unwillingness to budge and initiate between the two sides to resolve the conflict that they are facing. Departing from what is found in the field, human has a system called accommodation. Finchman \& Kashdan defines accommodation as a person's ability to manage and avoid the tendency to respond negatively to the behavior received from his opponent then turns them into a constructive experience (Linley \& Joseph, 2004). Such capabilities are then conceptualized by the experts as forgiveness (Santos, Adolescent, \& Forgiver, 1989).

Discussion of forgiveness one of them departs from a concept developed by Gilligan on the moral dilemma (Gilligan, 1997). This idea assumes that people solve problems by avoiding injustice and upholding justice. This injustice is then regarded as one of the things that people should be able to forgive (Gilligan, 1997). McCullough (1998) places forgiveness as the motivational changes of people to be motivated not to fight and avoid hostility (Peterson \& Seligman, 2004). Forgiveness is also a tendency to forgive the pain and discomfort that occurs in various situations (Kwok, Gu, \& Cheung, 2017). This forgiving process has a major impact on the repair of a loose relationship (Kato, 2016), (Braithwaite, Mitchell, Selby, \& Fincham, 2016), reducing our nature of determination and aggressiveness (Park, Enright, Essex, Zahn-waxler, \& Klatt, 2013), also becomes positive coping when the individual is faced with every problem, especially when they become the victim of being hurt (Costa \& Neves, 2017) \& (Wilson, Milosevic, Hart, \& Hibbard, 2008).

This forgiving behavior not only makes person able to survive in their relationship, but also able to create a closer brotherhood with his neighbor. Much literature explains that this forgiveness is a positive character that often people are not careful in feeling it. First, the concept of forgiveness is based on our perception of the world (being in a just world) that is an assumption that the person's behaving will have reply (Nudelman \& Nadler, 2017). If people feel that the pain they feel because someone else will get a worthy reply, then the tendency to behave forgiveness will also appear (Bartholomaeus \& Strelan, 2016). Second, forgiveness is something that we instinctively learn in life because it is so much internalized in religious and spiritual education of man. Islam teaches its people to behave forgiven like the nature possessed by Allah that is AlGhafoor (Peterson \& Seligman, 2004). Similarly, other religions teach forgiveness as teshuvah (Jewish), the law of moral causal \& effect (Budha), and dharma (Hindhu) (Peterson \& Seligman, 2004).

The process of forgiving basically can happen differently on each person. Someone does that as soon as they get an incident that does not wear, some also take a long time until the forgiveness actually happens. From the preliminary study, results by interviewing subjects who experienced a friendship conflict, this forgiveness process usually lasts more than a few days. The most logical reason is because the heartache they feel is not just they can forget. Even one of the subjects said that the process of forgiveness that he did occurs when the perpetrator or friend in question had died.

When a conflict occurs, the victim will feel negative emotions that vary in different levels on everyone. This resentment, hatred, and discomfort will be felt as a result of their inability to use appropriate coping. At this time they are at the stage of revengeful forgiveness (Santos et al., 1989). Some of them feel that what they get is also felt by the perpetrator in question (compensational forgiveness). Next, they feel that there are people outside of them who support them to forgive each other (expectational forgiveness). The religious factor also affects this forgiveness (lawful expectational forgiveness). Finally they realize that this forgiveness is their way to harmony and love each other (Hamer \& Penczek, 2017).

Many factors determine or even make it difficult for someone to forgive. Personality is one of the most influential aspects of this. The properties of perfectionism and the narcissistic personality that then makes people to hesitate to behave this way (Furman, Luo, \& Jr, 2017) \& (Fatfouta, Gerlach, Schröder-abé, \& Merkl, 2015). Those who arrogantly result in individuals not willing to forgive and refuse to behave prosocial (Fatfouta \& Schröder-abé, 2017). Individuals who get psychological trauma in their past also tend to be difficult to do forgiveness (Internet, 2017) \& (Fayyaz \& Ali, 2011). Other factors affecting the nature of this forgiving process is agreeableness personality that tends to like to do good and cooperative toward the conflict (Hilbig, Thielmann, Klein, \& Henninger, 2016) and consciousness (Rey \& Extremera, 2014). Contrast to the trait neuroticism who find it difficult to forgive (Maltby et al., 2008).

On the other hand, the process of forgiveness can take place quickly depending on how individuals perceive what they consider painful as the basis for becoming a better person. Individuals like this are considered to be mature in development and able to think ripe to the conflict that it faces (Steiner, Allemand, \& Mccullough, 2011). Individuals who have matured the development and mental will show the attitude of appreciation 
toward others, so that there is harmonization and prosperity in their mind (Strelan, Feather, \& Mckee, 2008).

Forgiveness is the most important aspect, especially in solving the conflicts of friendship. This is supported by other research that facilitates forgiveness as the best way to coping when victimized. Forgiveness correlates with gratitude and psychological well-being (Orbon, Mercado, \& Balila, 2015), enhances the meaning of individual life (Tongeren et al., 2015), and enhances the love and affection of fellow human beings (Strelan et al., 2008).

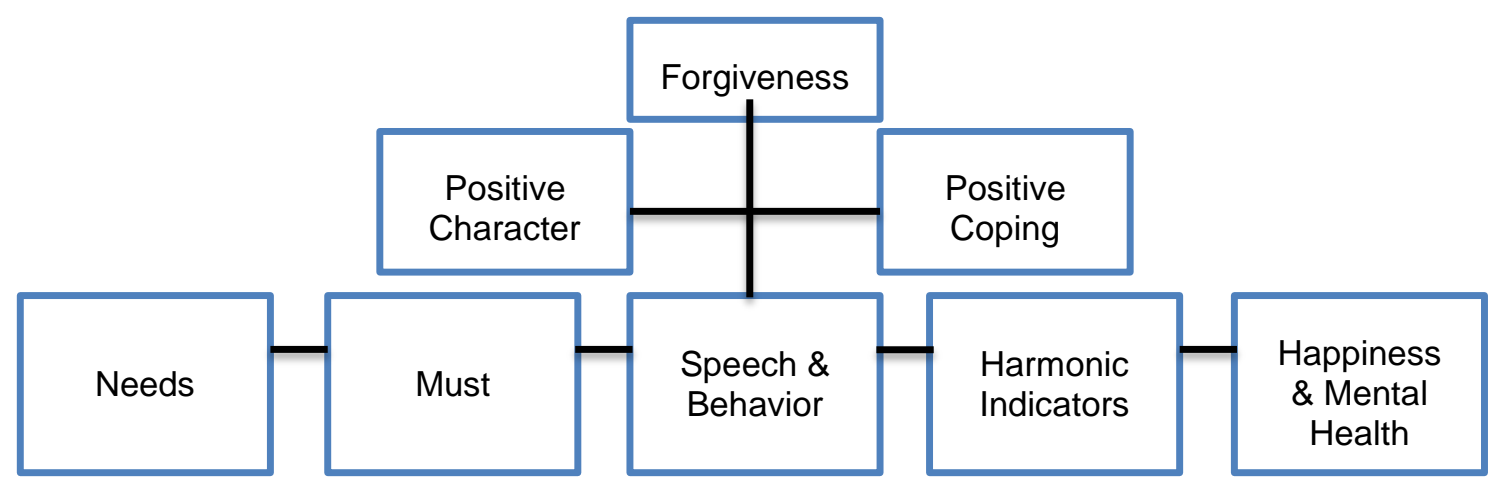

Fig. 1. Theoretical Mapping of Forgiveness

\section{METHODOLOGY}

\subsection{Problem Approach Method}

To create a good research, it is necessary to start from identifying the relevant issues and topics. Where the problem is taken based on field criteria and the researcher's interest in the phenomena that occur around him. In his own phenomenology research, Stanage (1987) said that there is an important aspect that must be considered in deciding called paradigm (Groenewald, 2004a). This paradigm will lead us as researchers in a wider and measurable view of what we will do. Paradigm itself is defined as a series of fundamental beliefs that guide us to the execution or action. According to Groenewald phenomenological research is indeed contrary to a very deterministic positive assumption and incapable of viewing subjects as a very rich source personally (Groenewald, 2004b). What should be considered is the focus of research based on the participants' perspective on the phenomena occurring in their development and growth and greatly contributes to their life processes. Human life process like an understanding of individual experience and exploring the relationship of the person's closeness in various situations and events or contexts (Hood, 2016).

Epoche. This is the first stage mentioned as the null hypothesis. One of them with bracketing of objective knowledge. While Giorgi states the epoche as to emphasize views on preconceptions and theoretical biases. Another goal is to do judgment, to capture biases, and to recall the experiences of the initial hypothesis (Woodard, 2004). There are several things to be contemplated (Finlay, 2012) when will do phenomenology process.
a. Improving good attitude towards phenomenology
b. Entering the subject world through a description of the experience
c. Giving deeply of implicit meanings
d. It requires a holistic phenomenon
e. Unifying or integrating frame references.

\subsection{Selecting a Research Sample}

Most studies in phenomenology use a purposive sampling approach. This means that sampling is based on the needs and objectives that have been planned by previous researchers. Samples are taken based on predetermined criteria and are judgmental sampling, there is a prior assessment of the samples to be taken. Not using a random system so that the chosen candidate is in accordance with the criteria and characteristics desired by previous researchers. In selecting and perfecting what participants need, researchers also include snowball sampling techniques to help get the best samples. Snowball sampling is a sampling method that is based to multiply the participants that is by asking someone informant or participant 
to recommend other participants for being interviewed (Babbie, 1995; Crabtree \& Miller, 1992 in (Groenewald, 2004a). A person known as a subject data search is referred to as key actors or key insiders. Historically known as the informant, who later experienced a narrowing of the meaning of the term. Neuman (2000) explains that the gatekeeper or the data seeker is a person who formally or informally has the authority to control those dimensions.

One of the advantages of phenomenological research is the existence of an agreement which is then often known as the term informant consent. This is a very important part in relation to the subject and its willingness. Groenewald (2004) also standardizes what should be and is included in the informant consent, including:
a. Participants are willing to take part in the research
b. The purpose of the study \& what procedures will be done
c. Risks and benefits to be gained
d. Consciously participants want to join
e. Participants may properly discontinue the study at any time
f. The procedures used should protect confidentiality and privacy.

\subsection{Method of Data Obtaining}

To obtain maximum data the researchers must pay attention to the theoretical part that at least can be a guide for the process of interviewing or retrieving data on phenomenology. At the stage of data collection should consider what kind of interview method will be used in research. Is that very formal or informal, whether highly structured or unstructured. This is very important because it will affect the specification of questions that will be asked to the participants concerned. Interviews should be conscious and open to one another. When the process is also important consider the duration and the agreements of what will be done. Miles and Huberman (1984) offer an important aspect to consider in obtaining and analyzing the data source is "memoing" (Groenewald, 2004a). These are writers' notes during the interview or observation process. Researchers can present what they find in a particular note. It can also be useful in maintaining and balancing what participants say with other objectivities that researchers find.

\subsection{Unit Problems}

In this study the units of problem to be studied are as follows:
a. The types of conflicts encountered
b. Duration of Forgiveness
c. Cognitive \& Behavioral accompaniment
d. Interpersonal dimensions
e. Self-accommodation
f. Supporting \& Barrier factors
g. Impact on physical and body health
h. Values and personal perspectives

\subsection{Data Excavation Instruments}

The relationship between the researcher and the subject in a qualitative interview are very important. One of them is the difference in background that is often the attention of researchers who will affect the quality of interviews. This aspect is also about the ethical relationship between the researcher and the subject. There are namely autonomy, vulnerability through misrepresentation, beneficence and non-maleficence, and Justice (Hewitt, 2007). The question was made based on the appropriate facts, using appropriate procedures and estimation and also based on the desire to generalize (Adams \& Manen, 2017).

\subsection{Probing Interview Questions}

Can you tell us what kind of conflict you experienced?

How do you feel when you get that unpleasant behaviour?

When and what situations make you think to forget about the resentment you received? 
How long will it take you to forget about the incident and what are the things you feel during the process? What responses do you make when the desire to forgive?

What about social support for the process you are experiencing?

What makes you absolutely sure that forgiveness will get a better solution?

What challenges do you find in the process of forgiveness?

What about your body's health before and after you do that?

What personal values do you apply to be forgiving?

Future expectations with the subject that ever made you hurt like what?

Why forgiveness is very important for you to do and generally by everyone?

\subsection{Data Analysis Technique}

Interview data should be recorded using a good tool and of course must get permission from the concerned. Every time the interview is done it must be coded. This helps in performing data specifications and differentiating them more easily. It should be ensured that the tool is both in quality and appearance, because to avoid technical problems. Environmental factors should also be considered to maintain sound quality and noise that may also occur.

\subsection{Data Explicitation}

Analyzing the data is part of doing the reduction of parts of the contents submitted into several parts. In this section data reduction will take place but must still maintain the integrity of the data essentially. There are five criteria done in doing data analysis, that is:
a. Dividing and reducing the phenomenological experience
b. Limiting the unit to be excavated
c. Dividing the unit by theme
d. Concluding the results of each interview and validating it
e. Filtering out the common themes and unique themes of all interviews and summarizing them.

Giorgi (1997) as adapted by Schweitzer in (Holroyd, 2001) Provide a clear picture of how the steps to be done when wanting to perform data analysis and drawing conclusions in phenomenological research. First is to understand the raw data, then form a clear profile picture. Profiles should consider NMUs (Natural Meaning Units), main themes, and constituent profile itself. Third is to do thematic index. The fourth to do the description and last is to construct a synthesis of the conclusions of the description.

\subsection{Data Analysis in Phenomenology}

Firstly is about reduction and imaginative variations. The description is then converted into the unit themes. Intuitive process to mark the meaning is also be given by the participants. Then we have to translate and specify the meaning of the unit. Then we transformed to the psychological language and identified as theme. It is also converted into a general structure. Validity refers to how other researchers see the researcher leading to the naming process. Finally we can analyze all raw data (Woodard, 2004).

\section{RESULTS}

\subsection{The Way of Research}

This research is a series of structured information digging with the main objective is to get a picture of the inexperience of individuals in the process of forgiving when a friendship conflict occurs. Phenomenology process applied in this research researcher will described in table of research flow below.

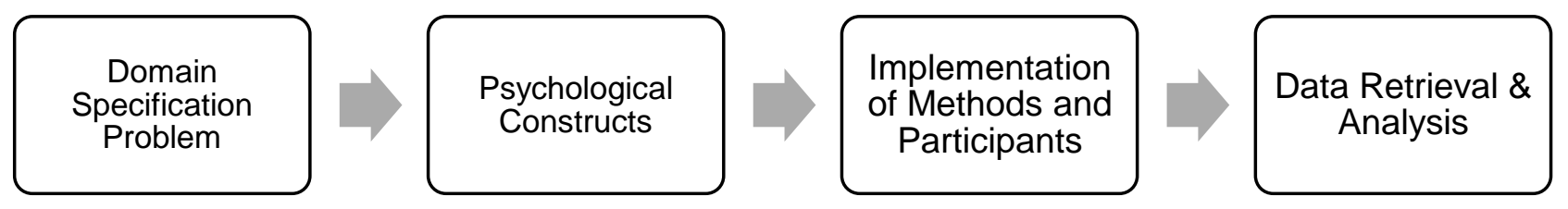

Fig. 2. Research Stages 


\subsection{Data Exposure}

The instrument used in this study is a semi structured interview where the end result is obtaining raw data in the form of a data transcript of interviewed descriptions results obtained in depth from what participants present. Data obtained by referring to the principle of ethical conduct research, where there has been agreement between researchers and informants in the study. The data obtained is raw data which will then be done member checking that aims to see the suitability between what is obtained with the actual facts of the subject. In this study the subjects were 3 people with each had obtained a research agreement and had checked the results before the data were analyzed. The data analyzed is data that has been validated and accountable so it is good enough to be interpreted.

\subsection{Transcripts of the Interview}

The data obtained from this phenomenological study come from 3 participants who have been considered to represent the criteria of researchers, those who have entered the stage of adult development and have experienced a conflict of friendship and there has been a process of forgiveness of what they feel.

Subject 1, male, age 22 years

When I see her my heart hurts again that I never send a message to her. Well the short message was arguably a war of words. And I am also carried away emotionally, and the point is, I feel the most right.

I was feeling troubled, busy, a lot of business too, so I do not think it's fair to blame all those problems to me.

Yes let the wound opened, if people do not want to see it is bandaged so that the wound was covered. So I was not to repeat myself, so I was afraid it would happen again.

I see it because of the nature of such characters, I once asked him, and said from what his behavior, the way he speaks, I see it like the behavior of the youngest children who are spoiled.

My initiative apologized to him, because I was afraid when I jumped later, so I initiated first apologize. However, there is however he keeps repeating his mistakes.

Yes maybe because of the factor if I myself I want to be changed for the better. Everyone has a good example of each. My example is Muhammad (our prophet), so I try to behave as he does, so I try to imitate,

The concerned has never said a word even to apologize, so far I'm just trying to forgive. I think consciously make mistakes yes apologize

Hope one of us must be able to respect others. Then we must know how to pass on good advice to others.

Subject 2, woman, age 25 years

Actually it has been twice, and not a problem but this time it is annoying and she should be a friend but she is not so

I feel hurt, so she wanted a scholarship list, then a publisher editor too.

Well of course disappointed, I thought got along with her, because we learned together, exchanged ideas, share each other. She might be little jealous to me and she may want to get a master's degree like me. There may be family factors, etc.

Well she used to talk to, never call but I never lifted, asking news all sorts, well answer her mediocre, ignorant how so.

One side I hurt but on the other side she is my friend. So supposing sin to me yes there will be a reply, so please let me have a reply on top.

Trying to strengthen myself, then I try to imagine if I were in his position she may be difficult with it.

I continue to believe whether or not there is a crime that reply or not 
Then in this month I tried to fix this relationship again, anyway again it's the holy month, Eid Al-Fitr is sure to meet too. Yeah, it's not good if it's a rage.

But maybe there is one side in my life that was so somewhat disturbed, rich mood well. So easy to change emotions

This is worse in my mind all sorts, the task is not finished, bad mood or others.

Whose name humans must be no harm. Moreover, we learn psychology, oh maybe her position again really urgent. So that's the key, while reflecting on what we have right now.

The process of forgiveness must be examined not only from me who is victimized, but also from the perspective of her who became the perpetrator. If suppose I only see from one side only, it is also not fair as well and not healthy for myself. Because often many reads the journal so much reflect on the positive things. So it's even more useful when we go to college.

Subject 3, male, age 25 years

When in conflict I feel victimized, and I feel always hurt. I do not know why I feel the most hurt.

Maybe because he is ignorant, people are not too sensitive yes so usual. Just because they are not in contact with each other are awkward

Actually I am one of those people who cannot revenge. The longest one week, and I am a person who cannot be angry. Well from that I feel so rich like this. Though he's my close friend. We already like friends everywhere together. Well that I immediately felt whether I was too selfish, or I was like a child

One of them friends say you are not dear friendship is long. Is it because already close what not dear. Continue also because I already know with his parents.

Usually because of her attitude. His attitude may be, because I am too sensitive, and he is too indifferent. Sometimes we think if you want to go back try to show if you apologize

When there is such a problem so unthinkable, so the task is not optimal because of the mind. I also so silent. I also do not focus on what to do.

I want to apologize directly, especially for our selfishness, we feel very selfish. Maybe he does not know what hurt me either. I still feel sorry when he's gone.

I feel that maybe everyone has forgiven me. Sometimes we already feel prestige or something. Well that is also important is we also start to contact or forgive first. Such as meeting or inviting the meeting first.

Of the information obtained from three subjects, then there are several themes that researchers explicit as the findings in the study.

\begin{tabular}{|l|l|}
\hline Unforgettable Event & Compensational \& Expectation \\
\hline Basic Personal Values & Positive Effort \\
\hline Restatements of Offender & Forgive as Love \& Harmony \\
\hline Understanding Offender & Mood \& Emotional Stability \\
\hline Cognitive \& Behavioral Accompaniment & Lack Motivation of Offender \\
\hline
\end{tabular}




\subsection{Discussion of Research Results}

Forgiveness as one of the important attributes in the course of individual conflict has provided a lot of important information in the process. Forgive as a process that is very difficult to do but in reality many of the participants who indirectly able to perform the process. Although the dynamics vary greatly from one to another. In general, the results of this study provide information that every person in conflict has a tendency to solve it well (Peterson \& Seligman, 2004). McCullough (1998) argues that the most important feature of this forgiveness process is that individuals feel very hurt and should avoid prolonged factors by eliminating feelings of annoyance, anger, and excessive emotional distress. All subjects feel sad, irritated, annoyed, and angry when they get unhappy treatment from their friends who are considered perpetrators of the events or conflicts they face. Like what the subjects say that what they feel is then categorized into the early stages of forgiveness is the process of expressing the hatred and the discomfort they feel. This is very disturbing to their life processes because this activity is the beginning of the imbalance of their activities (Peterson \& Seligman, 2004) \& (Boyle et al., 2015).

The various feelings and negative emotions felt by the three participants will be received in different ways. The first coding they feel is about emotional and mood stability. This aspect includes all feelings and moods when an individual gets the stress or illness he or she receives from the participant. Forgiveness is considered to be very important especially when the conflicts they face are accustomed to the test that individuals will always receive. The next theme is about the effect of the conflict they are experiencing on behavioral changes, the mechanism of activity schedules, relationships with those outside them in conflict, and sometimes life inappropriateness.

Three things that will be an indicator of how people can forgive others are the frequency, intensity, and type of hostility (Steiner et al., 2011). Frequency refers to the objective assessment of how many subjects get hurt. Intensity is the subjective perception experienced by the subject of the illness. The type of hostility leads to the kind that goes from the simplest to the deepest pain. The first subject tends to experience the longest forgiveness process than the other two participants. This is one of them, because of the inequalities of ideas and ideas that are exacerbated by the interaction of conflicts that have continued to the present day due to the activities they are undertaking. However, because of the spiritual experience experienced by the first participant is often obtained from his life, so a factor that adds to this process the faster progress. The two subsequent participants tend to have more maturity in facing problems. The process of forgiveness is very rapid, because both feel that a bad relationship will only get misery and the effect is even greater on their lives if it continues. By age these last two subjects are older than the first subject, so the tendency to forgive them is faster than the first (Steiner et al., 2011). In the third subject the experience of forgiveness occurs when the perpetrator in question has died. Although after the conflict it has been forgiven, but they have never been in direct communication again.

Other aspects from the overall theme obtained from these three subjects are about basic personal values, understanding of offenders, and positive effort. The first aspect that exists in the results of this study shows that the values constructed and obtained by each participant when his lifetime, will be one of their strengths to remain well behaved and in accordance with the demands of the existing norms. The first participant mentioned that he wanted to always imitate good behavior and good teachings about forgiving of his religion. The second participant hopes that God will repay all the bad things she received from others, while the third participant is more concerned that the goodness that he displays is a reflection of his forgiving and unvarnished personality.

The next two aspects are more to the cognitive domain as well as the behavior of both parties. Understanding of offenders means the ability to understand what actors actually feel again when doing actions that are not pleasing to us. The three subjects explain that when we begin to understand what the perpetrator's wrongdoing is, what should happen to the behavior, and what exactly is the greatest benefit we can receive from this, then the path of forgiveness will be even more likely to occur. Similarly, the third aspect is the positive effort. This indicates that by initiating the forgiveness process it will make us show acceptance and tolerance to what is received. Positive effort is not merely forgiving in our hearts, but there is a desire also to start contact and interaction with the concerned.

\section{CONCLUSIONS}

The results of this study conclude that although forgiveness is a difficult thing to do, at least there are three things that are key when people want to truly forgive. The three aspects are basic personal values, understanding of offenders, and positive effort. Basic personal values will be individual characteristics in resolving conflicts in accordance with the values of kindness, love, and humanity. Understanding of offender will improve our empathy toward feelings that others feel, while positive effort will be our step that 
forgiveness is not just saying a mere apology, but also sincerity in the heart which is then shown by the behavior willing to re-initiate and interact with the concerned. The hope is that the lives of both parties are better.

\section{ACKNOWLEDGEMENT}

Many thanks to Indonesia Endowment Fund for Education (LPDP), Ministry of Finance - Republic of Indonesia who has provided support and sponsorship so that I can get a chance to enroll in the postgraduate program of psychology at UGM.

\section{REFERENCE LIST}

Adams, C., \& Manen, M. A. Van. (2017). Teaching Phenomenological Research and Writing. https://doi.org/10.1177/1049732317698960

Bartholomaeus, J., \& Strelan, P. (2016). Just world beliefs and forgiveness : The mediating role of implicit theories of relationships. PAID, 96, 106-110. https://doi.org/10.1016/j.paid.2016.02.081

Boyle, G. J., Saklofske, D., \& Matthewes, G. (2015). Measures of Personality and Social Psychological Constructs. Oxford: Academic Press.

Braithwaite, S. R., Mitchell, C. M., Selby, E. A., \& Fincham, F. D. (2016). Trait forgiveness and enduring vulnerabilities: Neuroticism and catastrophizing in fl uence relationship satisfaction via less forgiveness. PAID, 94, 237-246. https://doi.org/10.1016/j.paid.2015.12.045

Costa, S. P., \& Neves, P. (2017). Forgiving is good for health and performance : How forgiveness helps individuals cope with the psychological contract breach. Journal of Vocational Behavior, 100, 124-136. https://doi.org/10.1016/j.jvb.2017.03.005

Costa, S. P., Neves, P., \& Neves, P. (2017). PT SC. Journal of Vocational Behavior. https://doi.org/10.1016/j.jvb.2017.03.005

Fatfouta, R., Gerlach, T. M., Schröder-abé, M., \& Merkl, A. (2015). Narcissism and lack of interpersonal forgiveness: The mediating role of state anger, state rumination, and state empathy q, 75, 36-40. https://doi.org/10.1016/j.paid.2014.10.051

Fatfouta, R., \& Schröder-abé, M. (2017). I can see clearly now : Clarity of transgression-related motivations enhances narcissists â $€^{\mathrm{TM}}$ lack of forgiveness. PAID, 105, 280-286. https://doi.org/10.1016/j.paid.2016.10.010

Fayyaz, F., \& Ali, M. (2011). Social and Comparison of forgiveness in clinical depressed, non-clinical depressed and normal people. https://doi.org/10.1016/j.sbspro.2011.10.018

Finlay, L. (2012). Unfolding the Phenomenological Research Process : Iterative Stages of "Seeing Afresh ." https://doi.org/10.1177/0022167812453877

Flanagan, K. S., Vanden, K. K., Ranter, J. M., \& Reich, H. A. (2012). The potential of forgiveness as a response for coping with negative peer experiences. Journal of Adolescence, 35(5), 1215-1223. https://doi.org/10.1016/j.adolescence.2012.04.004

Furman, C. R., Luo, S., \& Jr, R. S. P. (2017). A perfect blame : Con fl ict-promoting attributions mediate the association between perfectionism and forgiveness in romantic relationships. Personality and Individual Differences, 111, 178-186. https://doi.org/10.1016/j.paid.2017.01.052

Gilligan, E. (1997). The development of forgiveness in the context of, 393-402.

Groenewald, T. (2004a). A Phenomenological Research Design Illustrated, 3(1), 1-26.

Groenewald, T. (2004b). A Phenomenological Research Design Illustrated, 42-55.

Hamer, K., \& Penczek, M. (2017). "Humanum ignoscere est". The relationship of national and supranational identi fi cations with intergroup forgiveness, 105, 257-263. https://doi.org/10.1016/j.paid.2016.09.058

Hewitt, J. (2007). Ethical Components of Researcher - Researched Relationships in Qualitative Interviewing, 1149-1159.

Hilbig, B. E., Thielmann, I., Klein, S. A., \& Henninger, F. (2016). The two faces of cooperation : On the 
unique role of HEXACO Agreeableness for forgiveness versus retaliation. Journal of Research in Personality, 64, 69-78. https://doi.org/10.1016/j.jrp.2016.08.004

Holroyd, C. (2001). Phenomenological Research Method, Design and Procedure : A Phenomenological Investigation of the Phenomenon of Being-in-Community as Experienced by Two Individuals Who Have Participated in a Community Building Workshop, 1(April), 1-10.

Hood, R. (2016). Combining phenomenological and critical methodologies in qualitative research. https://doi.org/10.1177/1473325015586248

Internet, I. (2017). Computers in Human Behavior Psychological maltreatment, forgiveness, mindfulness , and internet addiction among young adults : A study of mediation effect, 72. https://doi.org/10.1016/j.chb.2017.02.037

Kato, T. (2016). Effects of partner forgiveness on romantic break-ups in dating relationships : A longitudinal study. PAID, 95, 185-189. https://doi.org/10.1016/j.paid.2016.02.050

Krause, N. (2015). Advances in Life Course Research Assessing the relationships among race, religion, humility , and self-forgiveness : A longitudinal investigation. Advances in Life Course Research, 24, 6674. https://doi.org/10.1016/j.alcr.2015.02.003

Kwok, S. Y. C. L., Gu, M., \& Cheung, A. P. S. (2017). Child Abuse \& Neglect A longitudinal study of the role of children ' $s$ altruism and forgiveness in the relation between parental aggressive discipline and anxiety of preschoolers in China. Child Abuse \& Neglect, 65, 236-247. https://doi.org/10.1016/j.chiabu.2017.02.004

Linley, P. A., \& Joseph, S. (2004). Positive Psychology in Practice. New Jersey: John Wiley \& Sons.

Maltby, J., Wood, A. M., Day, L., Kon, T. W. H., Colley, A., \& Linley, P. A. (2008). Personality predictors of levels of forgiveness two and a half years after the transgression, 42, 1088-1094. https://doi.org/10.1016/j.jrp.2007.12.008

Nudelman, G., \& Nadler, A. (2017). The effect of apology on forgiveness : Belief in a just world as a moderator, Personality and Individual Differences, 116, 191-200. https://doi.org/10.1016/j.paid.2017.04.048

Orbon, M., Mercado, J., \& Balila, J. (2015). Effects of forgiveness therapy on recovery among residents of drug rehabilitation centers. Procedia - Social and Behavioral Sciences, 165, 12-20. https://doi.org/10.1016/j.sbspro.2014.12.599

Park, J., Enright, R. D., Essex, M. J., Zahn-waxler, C., \& Klatt, J. S. (2013). Journal of Applied Developmental Psychology Forgiveness intervention for female South Korean adolescent aggressive victims. Journal of Applied Developmental Psychology, 34(6), 268-276. https://doi.org/10.1016/j.appdev.2013.06.001

Peterson, C., \& Seligman, M. E. P. (2004). Character Strengths and Virtues: A Handbook and Classification. Londong-England: Oxford Univerisity Press.

Rey, L., \& Extremera, N. (2014). Positive psychological characteristics and interpersonal forgiveness : Identifying the unique contribution of emotional intelligence abilities, Big Five traits, gratitude and optimism. Personality and Individual Differences, 68, 199-204. https://doi.org/10.1016/j.paid.2014.04.030

Riek, B. M., Luna, L. M. R., \& Schnabelrauch, C. A. (2014). Transgressors ' guilt and shame: A longitudinal examination of forgiveness seeking, 31(6), 751-772. https://doi.org/10.1177/0265407513503595

Rizvi, S., \& Bobocel, D. R. (2016). Promoting Forgiveness Through Psychological Distance, 7(8), 875-883. https://doi.org/10.1177/1948550616662122

Santos, M. J. D., Adolescent, T. H. E., \& Forgiver, A. S. (1989). The adolescent as forgiver.

Steiner, M., Allemand, M., \& Mccullough, M. E. (2011). Age differences in forgivingness: The role of transgression frequency and intensity. Journal of Research in Personality, 45(6), 670-678. https://doi.org/10.1016/j.jpp.2011.09.004

Strelan, P., Feather, N. T., \& Mckee, I. (2008). Journal of Experimental Social Psychology Justice and forgiveness : Experimental evidence for compatibility, 44, 1538-1544.

https://doi.org/10.1016/j.jesp.2008.07.014 
Tongeren, D. R. Van, Green, J. D., Hook, J. N., Davis, D. E., Davis, J. L., \& Ramos, M. (2015). Forgiveness Increases Meaning in Life, 6(1), 47-55. https://doi.org/10.1177/1948550614541298

Wilson, T., Milosevic, A., Hart, K., \& Hibbard, S. (2008). Physical Health Status in Relation to Selfforgiveness and Other-forgiveness in Healthy College Students. https://doi.org/10.1177/1359105308093863

Woodard, F. J. (2004). HYPNOTIC EXPERIENCING ', (1966), 887-904.

Woodyatt, L., \& Wenzel, M. (2013). Journal of Experimental Social Psychology The psychological immune response in the face of transgressions: Pseudo self-forgiveness and threat to belonging. Journal of Experimental Social Psychology, 49(6), 951-958. https://doi.org/10.1016/j.jesp.2013.05.016

Younger, J. W., Piferi, R. L., Jobe, R. L., \& Lawler, K. A. (2004). Dimensions of forgiveness : The views of laypersons, 21(6), 837-855. https://doi.org/10.1177/0265407504047843 